\title{
Neurobiología de la depresión mayor y de su tratamiento farmacológico
}

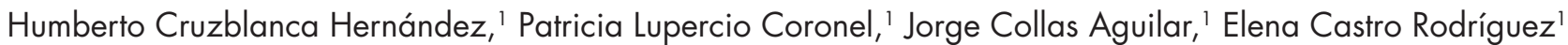

Actualización por temas

\section{ABSTRACT}

\section{Introduction}

The major depressive disorder (MDD) arises from the interaction of environmental, genetic and epigenetic factors, producing a deficit in monoaminergic transmission within the brain. However, our understanding of its pathophysiology is quite limited.

\section{Objective}

To reach an integrative view of the MDD pathophysiology, as well as the mechanisms of action of antidepressant drugs.

\section{Method}

We used the PubMed database to search for the documents by using the appropriate key words. Most of them are experimental research and molecular genetics and brain imaging studies in humans.

\section{Results}

The pathophysiology of MDD is characterized by: i) shrinkage of the cingulate anterior cortex; ii) hyper-metabolism of the $\mathrm{Cg} 25$ area; iii) lower expression of the $5-\mathrm{HT}_{1 \mathrm{~A}}$ receptor; iv) enhanced expression of monoamine oxidase A. Besides, certain gene polymorphisms are strongly linked to the pathophysiology, and there is evidence that $5-\mathrm{HT}_{\mathrm{IA}}$ receptor expression is reduced by psychological stress. Antidepressants reverse the hyper-metabolic state of $\mathrm{Cg} 25$, stimulate neurogenesis and the CAMP pathway. We found that imipramine increases and reduces the expression of $G_{u s}$ and $G_{a z}$, respectively (data no published).

\section{Discussion and conclusion}

The disruption in monoaminergic transmission could be mediated by: i) the G1463A hTPH2 polymorphism that reduces the serotonin synthesis; ii) the $\mathrm{C}(-1019) \mathrm{G} 5-\mathrm{HT}_{1 \mathrm{~A}}$ polymorphism that increases the receptor expression in the dorsal rafe, and reduces serotonin release; iii) an increase in monoamine degradation. The reduced $5-\mathrm{HT}_{1 \mathrm{~A}}$ expression is discussed considering its inhibitory properties in the prefrontal cortex. The effects of imipramine on $G_{u s}$ and $G_{u z}$ are in agreement with the antidepressant-induced stimulation of the CAMP pathway.

Key words: Major depression, antidepressant drugs, serotonin, stress, neurons.

\section{RESUMEN}

\section{Introducción}

La depresión mayor (DM) se debe a la interacción de factores ambientales, genéticos y epigenéticos, que atenúan la transmisión monoaminérgica en el cerebro. Sin embargo, poco se conoce sobre los mecanismos fisiopatológicos que subyacen a ella.

\section{Objetivo}

Proponer una visión integral sobre la fisiopatología de la DM y los mecanismos de acción de los fármacos antidepresivos.

\section{Método}

Se empleó la base PubMed para la búsqueda bibliográfica. La mayoría son investigaciones experimentales y estudios de genética molecular o de imágenes cerebrales en humanos.

\section{Resultados}

La DM se asocia con: i) menor volumen de la corteza cingulada anterior; ii) hiper-metabolismo del área $\mathrm{Cg} 25$; iii) menor expresión del receptor $5-\mathrm{HT}_{1 \mathrm{~A}}$; iv) mayor expresión de la monoamino oxidasa $\mathrm{A}$. Algunos polimorfismos están asociados a la fisiopatología. El estrés crónico reduce la expresión del $5-\mathrm{HT}_{1 \mathrm{~A}}$. Los antidepresivos atenúan el hiper-metabolismo del área $\mathrm{Cg} 25$, estimulan la neurogénesis y activan la vía del AMPc. Encontramos que la imipramina aumenta y reduce la expresión de $G_{a s}$ y $G_{a z}$, respectivamente (datos sin publicar).

\section{Discusión y conclusión}

El déficit en la transmisión monoaminérgica puede deberse a: i) el polimorfismo G1463A en el gen de la enzima $h T P H 2$ que reduce la síntesis de serotonina; ii) el polimorfismo $\mathrm{C}(-1019) \mathrm{G}$ en el gen del receptor $5-\mathrm{HT}_{1 \mathrm{~A}}$, aumentando su transcripción en el rafé e implicando menor liberación del neurotransmisor; iii) mayor degradación de las monoaminas. La menor expresión del receptor $5-\mathrm{HT}_{1 \mathrm{~A}}$ se discute considerando su acción inhibitoria en la corteza prefrontal. Los cambios en la expresión de $G_{a s}$ y $G_{a z}$ coinciden con la estimulación de la vía del AMPc.

Palabras clave: Depresión mayor, fármacos antidepresivos, serotonina, estrés, neuronas.

Centro Universitario de Investigaciones Biomédicas, Universidad de Colima, Colima, Col., México.

Correspondencia: Dr. Humberto Cruzblanca. Centro Universitario de Investigaciones Biomédicas, Universidad de Colima. Av. 25 de julio 965, Villas San Sebastián, 28045, Colima, Col., México. E-mail: cruzblan@ucol.mx

Recibido primera versión: 9 de diciembre de 2014. Segunda versión: 8 de octubre de 2015. Tercera versión: 26 de noviembre de 2015 . Aceptado: 12 de enero de 2016 


\section{INTRODUCCIÓN}

El principal trastorno del estado de ánimo es la depresión mayor (DM). La literatura especializada sobre el tema contiene varias revisiones que abordan distintos aspectos como su epidemiología, genética, etiología y fisiopatología. ${ }^{1,2}$ Sin embargo, no se ha propuesto una posible conexión entre los más recientes hallazgos a nivel celular y molecular, con los cambios anatómico-funcionales que ocurren en el cerebro de los pacientes con DM. Los objetivos de esta revisión son: 1. proponer una visión integral sobre la fisiopatología de la DM y los mecanismos de acción de los fármacos antidepresivos y 2. discutir la evidencia reciente que sustenta a las dos hipótesis neurobiológicas de la DM: la monoaminérgica, con énfasis en el componente serotoninérgico, y la neurotrófica.

\section{MÉTODOS}

La búsqueda bibliográfica se hizo en PubMed empleando las siguientes palabras clave: depresión mayor, fármacos antidepresivos, serotonina, estrés y neuronas. Los criterios de inclusión fueron: i) publicaciones enfocadas en la fisiopatología molecular, celular y sistémica de la DM; ii) estudios experimentales en neuronas aisladas y/o in situ, sobre los mecanismos de acción de los fármacos antidepresivos; iii) estudios farmacológicos pre-clínicos y clínicos; iv) trabajos publicados en su mayoría en los últimos 10 años.

Como se discute en la presente revisión, la fisiopatología de la DM incluye un mecanismo neurotrófico. En este contexto hay evidencia de que las proteínas $G$ heterotriméricas (proteínas $\mathrm{G}$ ) regulan las vías de señalización intracelular activadas por receptores a factores neurotróficos, convirtiendo a las proteínas $\mathrm{G}$ como posibles blanco molecular de los fármacos antidepresivos. Por lo anterior, un objetivo adicional de este trabajo es reportar el efecto del antidepresivo imipramina sobre la expresión de las subunidades $\alpha$ $(\mathrm{G} \alpha)$ de las proteínas G. Por lo tanto, los resultados de la figura 1 se obtuvieron empleando la siguiente metodología: se inyectaron seis ratas macho (Wistar; 3 semanas) por vía intraperitoneal con solución salina $(n=3)$ o imipramina $(n$ = 3) $(10 \mathrm{mg} / \mathrm{Kg})$ por 21 días. Después, se anestesiaron y decapitaron para disecar los ganglios cervicales superiores. El protocolo fue aprobado por el Comité de Ética y Bioseguridad de la Universidad de Colima. Se removió la cápsula de tejido conectivo y cada par de ganglios se depositaron en tubos de PCR con $1 \mathrm{ml}$ de trizol. La transcripción inversa se realizó con el kit SuperScript TM III (Invitrogen). Para la PCR en tiempo real se utilizó el kit LightCicler Fast Start

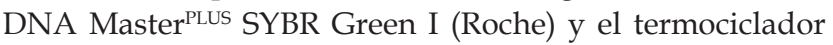
LightCycler 1.5 (Roche); los primers se diseñaron con salto de intrón. De las curvas de amplificación se obtuvo el parámetro "Ct" para normalizar la expresión de cada $\mathrm{G} \alpha(\alpha)$ a la del gen constitutivo (actina). La expresión relativa $(\alpha$ / actina) se empleó para cuantificar el cambio en la expresión, dividiendo el valor obtenido en las ratas inyectadas con solución salina ( $\alpha$ /actina) $)_{c}$ entre el valor con imipramina $(\alpha /$ actina $)_{\text {imi; }}$ si el cociente es mayor a uno significa aumento en la expresión y viceversa.

\section{Síntomas de la depresión mayor y criterios de diagnóstico}

La DM se caracteriza por episodios en los que las emociones y pensamientos negativos coexisten con déficit cognitivo y alteraciones en el apetito, la libido y el sueño. El instrumento de diagnóstico preferido en los Estados Unidos de América y en México es el Manual Diagnóstico y Estadístico de los Trastornos Mentales (DSM-IV). El manual incluye los siguientes síntomas: sentimientos de tristeza, desesperanza, inutilidad y culpa; baja autoestima; pensamientos negativos centrados en el suicidio; déficit cognitivo afectando la motivación, la atención selectiva, la memoria episódica y de trabajo y una menor capacidad de pensamientos reflexivos; irritabilidad, disforia y anhedonia. Los síntomas neurovegetativos incluyen menor o mayor apetito, fatiga y alteraciones del ciclo vigilia-sueño. El diagnóstico se establece cuando al menos cinco de los anteriores síntomas coexisten y persisten por lo menos durante dos semanas. En el 2013 apareció el DSM-5, el cual preserva el núcleo de síntomas pero se reconoce la comorbilidad con la ansiedad; otra novedad es que elimina el criterio de exclusión del duelo. En cualquier caso, el diagnóstico sigue siendo subjetivo dificultando el estudio de la etiología, la fisiopatología y el tratamiento de la DM. Sin embargo, los avances en las neurociencias eventualmente permitirán reformular desde bases más científicas (v. gr. proponiendo marcadores moleculares o biológicos) la nosología y etiología de los trastornos depresivos. La DM causa severa discapacidad en el contexto ocupacional, educativo y social, y se estima que en el año 2020 será la segunda causa de discapacidad en la población mundial y seguirá siendo la primera en los países industrializados. ${ }^{3,4}$

\section{Epidemiología y factores de riesgo}

En México, la encuesta de epidemiología psiquiátrica del 2002-2003 estimó una prevalencia del 4.5\% en la población adulta y de $1.7 \%$ antes de los 18 años., 5 Globalmente la prevalencia en la mujer es mayor que en el hombre, en una proporción de 2:1. Por ejemplo, en México la prevalencia en la población adulta es de $5.8 \%$ en mujeres y $2.5 \%$ en hombres y esta proporción se mantiene para la DM con inicio temprano $(2.4 \%$ en mujeres y $1.0 \%$ en hombres $) .5,6$

El consenso actual es que la DM se origina por la interacción de factores genéticos, epigenéticos y ambientales que eventualmente alteran la bioquímica, la citoarquitectura y la función de áreas específicas del cerebro. ${ }^{7-10}$ Aquí se analizan dos polimorfismos por su posible relevancia fisiopatológica: 
i) el polimorfismo G1463A del gen para la enzima triptófano hidroxilasa tipo 2 humana (hTPH2) y ii) el polimorfismo $\mathrm{C}(-1019) \mathrm{G}$ en el gen del receptor a la serotonina (5-HT) $5-\mathrm{HT}_{1 \mathrm{~A}}$. Dentro de los factores medioambientales se considera al estrés crónico (físico o psicológico) como factor de riesgo para la DM. Esta asociación parte de la observación de que cerca del $50 \%$ de los individuos con DM muestran hipercortisolemia. ${ }^{11-13}$ Estos hallazgos sugieren que la disregulación del eje hipotálamo-pituitaria-corteza adrenal (HPA) es un factor neuroendócrino que contribuye a la etiología de la DM. ${ }^{14}$

\section{Cambios anatómicos y metabólicos en el cerebro de individuos con DM}

La heterogénea sintomatología de la DM sugiere la participación de distintas áreas cerebrales. Por citar sólo dos, la disfunción de la corteza prefrontal (CPF) dorsolateral estaría afectando funciones cognitivas como el razonamiento, la planeación y la toma de decisiones (figura 2). Por su parte, las áreas orbitofrontal y medial de la $\mathrm{CPF}$, al participar en la regulación de la experiencia emocional, contribuirían al componente afectivo del síndrome. A continuación se discuten los hallazgos obtenidos con imágenes cerebrales por resonancia magnética (RM) y/o tomografía por emisión de positrones (PET), revelando las anormalidades anatómico-funcionales más frecuentes.

\section{Cambios en el volumen cortical y subcortical: estudios con RM}

Uno de los cambios estructurales es la reducción del hipocampo. ${ }^{15-19}$ El decremento promedio es del 8-10\%, siendo el cambio tanto bilateral como sólo en uno de los hemisferios. También se reporta una reducción significativa unicamente en pacientes que tuvieron episodios depresivos recurrentes, ${ }^{18}$ o bien el decremento se correlaciona inversamente con la duración del episodio depresivo. ${ }^{19}$ Otros estudios no reportan cambios en el volumen hipocampal, ni tampoco confirman la relación inversa entre la duración del episodio depresivo y el grado de reducción del volumen. ${ }^{16,20}$ Esta evidencia limita la importancia fisiopatológica de la reducción del hipocampo: i) los pacientes en remisión siguen mostrando menor volumen hippocampal; ${ }^{21}$ ii) la reducción también se observa en la esquizofrenia y en el trastorno bipolar, ${ }^{16,22}$ es decir, este cambio neuroanatómico no es exclusivo de la DM. Para conciliar estas observaciones se propone que la reducción del hipocampo no causa el primer episodio depresivo pero se convierte en un factor de recurrencia y de eventual cronicidad del síndrome depresivo. ${ }^{23}$

Otra área donde también se reduce la materia gris es la corteza cingulada anterior (CCA), específicamente en la zona ventral al genu del cuerpo calloso (corteza subgenual). La reducción es prominente (20-40\%) en pacientes con ante- cedentes familiares de DM. ${ }^{24}$ También la RM revela menor volumen de materia gris en la CPF orbital. ${ }^{25}$ Estas observaciones in vivo concuerdan con estudios post-mortem. Por ejemplo, Öngür ${ }^{26}$ encontró menor número de células gliales en la corteza subgenual Cg24; la reducción es más pronunciada en sujetos con DM (24\%) o enfermedad bipolar (41\%) con un claro perfil familiar. En este estudio los pacientes con esquizofrenia no mostraron variación de la densidad celular, sugiriendo que la menor densidad glíal es una anormalidad relacionada con la DM y otros síndromes afectivos. Cabe mencionar que la corteza subgenual y la CPF orbital al procesar información de las áreas de asociación sensorial, como de la corteza insular, la integran para generar la conducta emocional y afectiva. ${ }^{27,28}$

\section{Cambios funcionales en la DM: estudios con PET}

En coincidencia con el menor volumen de la corteza subgenual, el PET revela una menor actividad metabólica en esta área cortical. ${ }^{29}$ Sin embargo, cuando la imagen se corrige por el menor volumen, el área $\mathrm{Cg} 25$ revela hiper-metabolismo respecto de los individuos control. ${ }^{16}$ Es muy probable que esta hiperactividad contribuye a la conducta depresiva porque: 1. cuando a individuos sanos se les provoca un sentimiento de profunda tristeza también aumenta la actividad de $\mathrm{Cg} 25,{ }^{30}$ 2. los fármacos antidepresivos reducen el hiper-metabolismo de $\mathrm{Cg} 25$ o de otras áreas de la CPF, tanto en individuos con DM como en pacientes depresivos con enfermedad de Parkinson, ${ }^{16,31-34}$ 3. la estimulación eléctrica de $\mathrm{Cg} 25$ revierte la sintomatología depresiva. ${ }^{35,36}$

En la amígdala también aumenta la actividad metabólica. ${ }^{37}$ Esta alteración funcional no ocurre en la esquizofrenia o en síndromes de ansiedad como el obsesivo-compulsivo, las fobias y el trastorno de pánico. ${ }^{7}$ Hay evidencia de que el aumento de la actividad amigdalina antecede a la recaída de la sintomatología depresiva en pacientes bajo el protocolo de depleción del triptófano. ${ }^{38}$

\section{Neurobiología de la depresión mayor}

La hipótesis monoaminérgica. Esta hipótesis es el marco conceptual predominante que aborda la fisiopatología de la DM y establece que el síndrome se origina por la menor disponibilidad de monoaminas en el cerebro, principalmente de 5-HT y noradrenalina (NA). La hipótesis originalmente se basa en que la mayoría de los fármacos antidepresivos aumentan el nivel cerebral de 5-HT y NA mediante la inhibición de su recaptura o de su degradación enzimática. Estudios recientes aportan mayor sustento a la hipótesis. Por ejemplo, imágenes con PET revelan que los pacientes con DM muestran mayor expresión de la monoamino-oxidasa A (MAO-A) en la CPF, la corteza temporal, el hipocampo, el tálamo, el núcleo accumbens (NAc) y el mesencéfalo. ${ }^{39}$ Este 

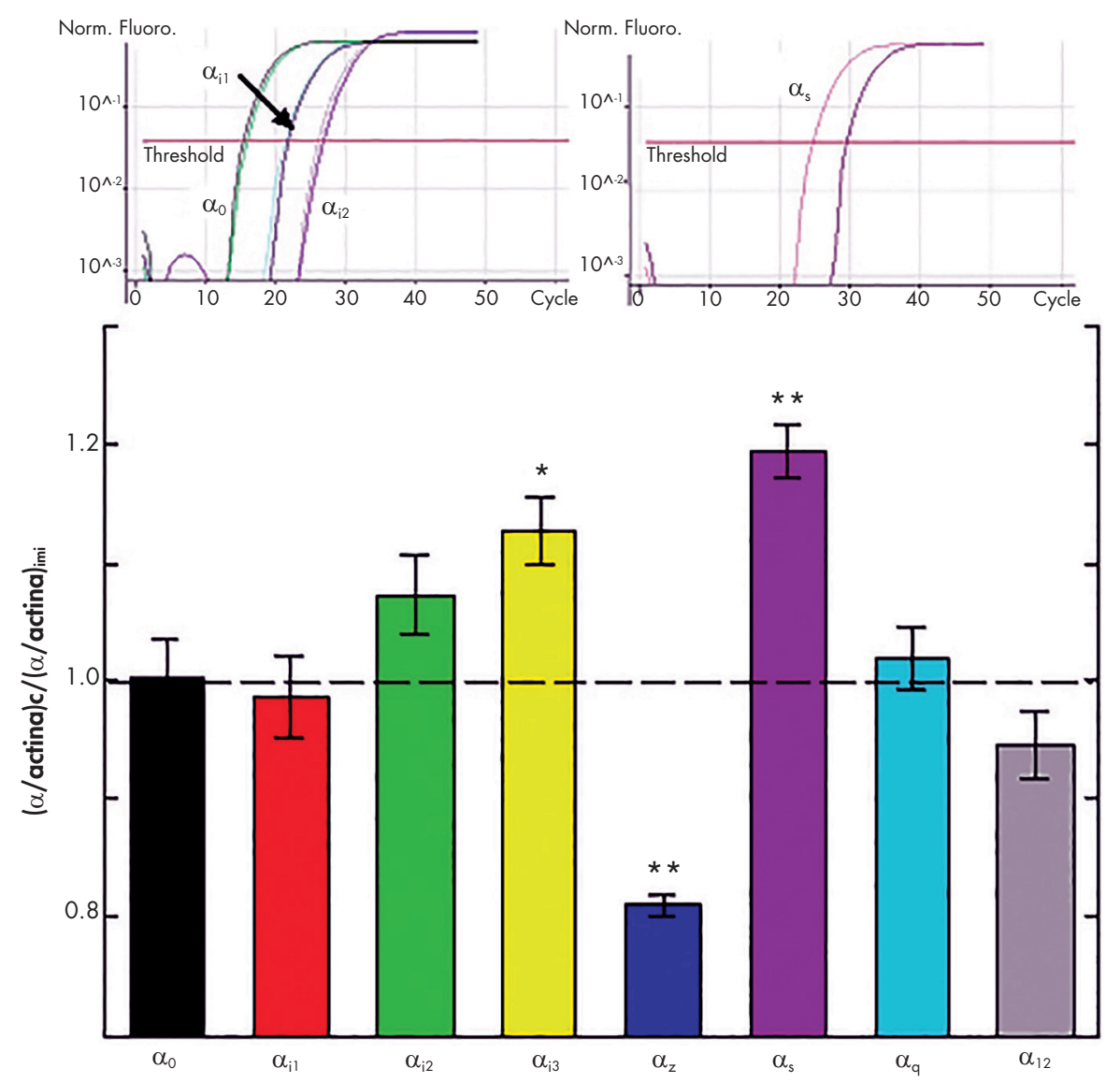

Figura 1. Efecto de la imipramina sobre la expresión de las subunidades $G_{\alpha}$ de las neuronas del ganglio cervical superior. En la parte superior se muestra las curvas de amplificación de los transcritos de $G_{a, 0}, G_{a i l}$ y $G_{a i 2}$ (panel izquierdo) y $G_{u s}$ (panel derecho). Nótese que la imipramina solo produce un corrimiento a la izquierda (trazo rosa) de la curva de amplificación de $G_{a s}$ respecto al tratamiento con solución salina (trazo fucsia). La gráfica resume (promedio \pm error estándar) el cambio en el nivel de expresión de las subunidades $G_{a}$. Nótese que el tratamiento crónico con imipramina robustamente aumenta la expresión de $G_{a s}$ y reduce la expresión de $G_{a z}$. Se indican los cambios estadísticamente significativos al $95 \%\left({ }^{*}\right) \circ 99 \%\left({ }^{* *}\right)$ de confianza (t de student pareada).

hallazgo hace suponer que la mayor tasa de degradación de 5-HT y NA es uno de los mecanismos fisiopatológicos que atenúa la transmisión monoaminérgica. Por su parte, el polimorfismo G1463A en el gen de la hTPH2 sugiere que el déficit serotoninérgico reside en la síntesis de 5-HT, ya que el correspondiente cambio de aminoácido resulta en la pérdida del $80 \%$ de la función enzimática. ${ }^{40}$ La asociación con la DM se confirma cuando en un grupo de 87 pacientes, el $10 \%$ portaba el polimorfismo G1463A, un porcentaje significativamente mayor al valor encontrado (1\%) en la muestra $(\mathrm{n}=219)$ de individuos sanos. ${ }^{40}$ Una evidencia clínica que apoya la hipótesis monoaminérgica proviene de estudios en pacientes sometidos al protocolo de depleción del triptófano (Trp) cerebral. Una predicción del paradigma es que la depleción facilita la recaída depresiva sólo en aquellos pacientes que respondieron al tratamiento con los inhibidores selectivos de la recaptura de 5-HT (SSRIs). Un meta-análisis de 45 estudios publicados hasta el 2006 revela resultados consistentes con la hipótesis. ${ }^{41}$

Es limitado el número de estudios cuando se reduce el nivel cerebral de NA y dopamina, sin embargo los datos apuntan en la misma dirección que en la depleción del Trp. ${ }^{41,42}$ Una evidencia a favor del componente noradrenérgico proviene de estudios post-mortem en donde se midió la unión de un ligando del transportador de NA en el locus coeruleus (LC). En una muestra de pacientes con DM se encontró una menor densidad del transportador respecto a los sujetos control. ${ }^{43}$ Se postula que este cambio es resultado de la menor biodisponibilidad de la NA en la sinapsis, lo que es plausible considerando que la mayor expresión de la MAO-A en el mesencéfalo ${ }^{39}$ estaría incrementando la degradación enzimática de la NA. Otro estudio en el LC reporta aumento en la densidad de receptores $\alpha_{2}$-adrenérgicos (su impacto funcional se discute más adelante) ${ }^{44}$ 


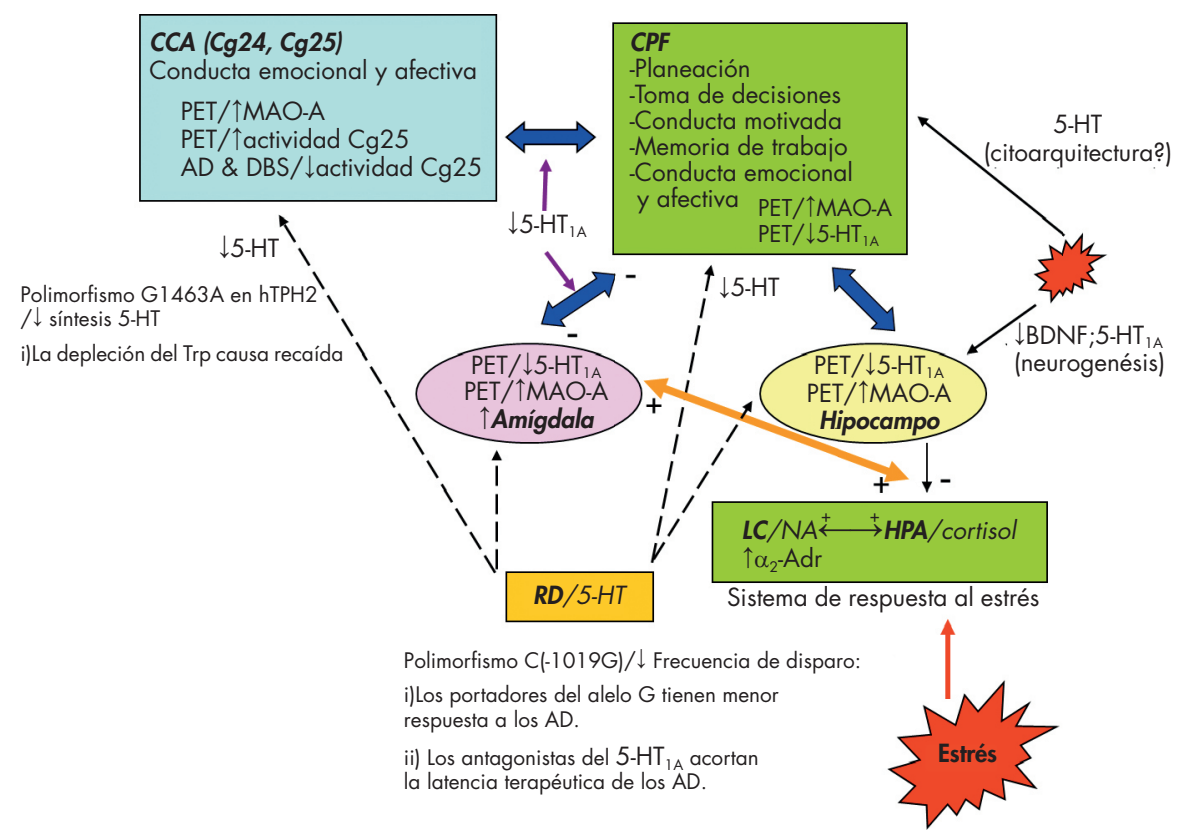

Figura 2. Integrando la evidencia básica y clínica de la DM. Se propone que el déficit en la transmisión monoaminérgica puede deberse a: i) la menor síntesis (polimorfismo G1463A) o liberación (polimorfismo C-1019G) de 5-HT; ii) aumento en la expresión de la MAO-A; iii) menor liberación de NA, por la mayor ( $\uparrow$ densidad de receptores a2-adrenérgicos (a2-Adr). El estrés reduce (flechas violeta) la densidad post-sináptica del receptor $5-\mathrm{HT}_{1 \mathrm{~A}}$, un cambio molecular consistente con el hiper-metabolismo del área $\mathrm{Cg} 25$ y la amígdala; probablemente revelando la disfunción (flechas azules) de los circuitos intra-corticales (v. gr. entre la CCA y CPF y otras áreas de asociación), como límbico-corticales. Los fármacos antidepresivos (AD) o la estimulación cerebral profunda (DBS) revierten el hiper-metabolismo de Cg25. La mayor actividad amigdalina puede potenciar (flecha naranja) la desregulación del eje HPA inducida por el estrés crónico. En el hipocampo el estrés reduce la expresión del BDNF y produce atrofia neuronal, pero también reduce la neurogénesis, por la menor expresión del BDNF y del 5-HT $1 \mathrm{~A}$. En la corteza, el estrés también afecta procesos de plasticidad sináptica y celular. Desde luego los mecanismos aquí planteados requieren de su directa valoración experimental.

La hipótesis neurotrófica. Esta hipótesis propone que la DM también se debe a la atrofia neuronal producto de la menor expresión del factor de crecimiento derivado del cerebro (BDNF). ${ }^{45}$ También propone que el estrés crónico disregula al eje HPA propiciando la exposición sostenida del tejido nervioso al cortisol y, con ello, la inhibición de la expresión del BDNF.7 Estudios post-morten aportan evidencia del mecanismo neurotrófico, pues se ha observado una menor expresión del BDNF y de su receptor TrkB en el hipocampo y la CPF de pacientes con DM, respecto a individuos sin padecimiento psiquiátrico al momento del deceso. ${ }^{46}$ Otro estudio reporta que pacientes con DM bajo tratamiento farmacológico muestran una mayor expresión del BDNF en el hipocampo, comparado con pacientes sin tratamiento. ${ }^{47}$

El resto de la evidencia proviene de estudios en roedores sometidos a estrés crónico. Un efecto común de los paradigmas de estrés es la menor expresión del BDNF y de su receptor TrkB en el hipocampo, mientras que la administración crónica de antidepresivos revierte el efecto del estrés sobre ambas proteínas. ${ }^{48-50}$ Además, los antidepresivos reducen el daño inducido por el estrés sobre la arborización dendrítica de las neuronas piramidales del hipocampo ${ }^{51,52}$ y estimulan la neurogénesis. ${ }^{53,54}$
La evidencia conductual proviene de modelos murinos de conducta depresiva. Por ejemplo, se cree que la prueba del nado forzado (FST por sus siglas en inglés) mimetiza la conducta de desesperanza del humano, y a pesar de su simpleza metodológica tiene gran valor predictivo de la eficacia terapéutica de los antidepresivos. ${ }^{55}$ Con la FST se reporta que la inyección de BDNF (un día antes de la prueba) en el hipocampo de la rata tiene efecto antidepresivo con eficacia similar al tratamiento farmacológico. ${ }^{56}$ Sin embargo, este efecto conductual agudo del BDNF contrasta con el hecho de que sólo el tratamiento crónico (21 días) con antidepresivos aumenta la expresión del BDNF y su receptor en esta misma especie. ${ }^{49}$ Es decir, el desfase entre el efecto conductual en la FST y génico del BDNF debe tomarse con reserva como sustento de la hipótesis neurotrófica.

\section{Receptores y rutas de señalización alteradas en la DM}

A continuación se discute la posible relevancia fisiopatológica del receptor $5-\mathrm{HT}_{1 \mathrm{~A}}$, un receptor que señaliza vía la familia $G_{i}$ de las proteínas $G$, ya que dependiendo de su densidad y localización pre- o post-sináptica tiene un 
impacto diferencial en el déficit de la transmisión serotoninérgica.

\section{A) Auto-receptor $5-H T_{1 A}$}

El polimorfismo C(-1019)G en el promotor del gen del receptor $5-\mathrm{HT}_{1 \mathrm{~A}}$ revela otro mecanismo fisiopatológico de la DM. Este cambio de nucleótido provoca su transcripción diferencial en el SNC, pues los portadores del alelo G tienen mayor densidad del receptor en el rafé dorsal (RD) y mayor asociación con la DM. ${ }^{57} \mathrm{El}$ grado de expresión del auto-receptor depende de la composición alélica, acorde con el genotipo CC $<$ CG $<$ GG. ${ }^{58}$ Además, los portadores del alelo G muestran una menor respuesta terapéutica a los antidepresivos. ${ }^{59}$ Para ponderar el impacto de la mayor densidad del auto-receptor $5-\mathrm{HT}_{1 \mathrm{~A}}$ basta decir que éste tiene un efecto inhibitorio en las neuronas del RD, limitando su frecuencia de disparo a un rango de $2-4 \mathrm{~Hz} .{ }^{60} \mathrm{El}$ férreo control sobre la tasa de disparo determina que el receptor $5-\mathrm{HT}_{1 \mathrm{~A}}$ controle desde el soma neuronal la liberación de 5-HT en la corteza cerebral y el sistema límbico. En consecuencia el polimorfismo C(-1019)G estaría provocando una menor liberación de 5-HT.

Aun cuando no hay una prueba directa del anterior mecanismo fisiopatológico, sí hay alguna evidencia clínica que lo apoya. Por ejemplo, se sabe que los antagonistas del 5- $\mathrm{HT}_{1 \mathrm{~A}}$ reducen la latencia terapéutica de los antidepresivos. ${ }^{61,62}$ Esta sinergia clínica obedece a que los SSRIs desensibilizan al auto-receptor $5-\mathrm{HT}_{1 \mathrm{~A}}$ por un mecanismo que implica su desacoplamiento con la proteína $\mathrm{G}$ y no vía la disminución en la densidad del receptor. ${ }^{63-65}$ En conclusión, la atenuación de la señalización del auto-receptor $5-\mathrm{HT}_{1 \mathrm{~A}}$ puede lograrse a través de la desensibilización o por medio de sus antagonistas. En ambos casos el resultado es que las neuronas del RD se liberan de su auto-inhibición.

\section{B) Receptor post-sináptico $5-H T_{1 A}$}

Estudios con PET en pacientes no tratados con antidepresivos revelan consistentemente una menor densidad del receptor $5-\mathrm{HT}_{1 \mathrm{~A}}$ en la $\mathrm{CPF}$, el hipocampo y la amígdala. ${ }^{66-69}$ Este cambio molecular también ocurre en la CCA tanto de pacientes cuyo diagnóstico es algún síndrome de ansiedad, como en aquellos que padecen ansiedad y depresión. ${ }^{70,71}$ Esto es de esperarse porque la co-morbilidad entre la ansiedad y la depresión es la regla. ${ }^{30}$

Los receptores a la 5-HT que mayormente se expresan en la CPF son el 5- $\mathrm{HT}_{1 \mathrm{~A}}$ y el 5- $\mathrm{HT}_{2 \mathrm{~A}}$; el primero se localiza en el soma y las dendritas basales de las neuronas piramidales, mientras que el segundo se ubica en la dendrita apical. ${ }^{72-74}$ En estas neuronas el 5- $\mathrm{HT}_{1 \mathrm{~A}}$ estimula un eflujo de $\mathrm{K}^{+}$a través de canales tipo GIRK. ${ }^{72,73,75}$ La acción inhibitoria incluye a las neuronas de las capas II y III de la CPF. ${ }^{75}$ Por lo tanto, la menor densidad post-sináptica del 5- $\mathrm{HT}_{1 \mathrm{~A}}$ puede implicar que en la DM suceda una alteración en el procesamiento de la información intracortical e interhemisférica, así como en la retroalimentación entre la corteza y el sistema límbico (figura
2). Esta disfunción explicaría ciertos hallazgos realizados por fMRI que revelan un decremento en la comunicación entre la amígdala y la CCA. ${ }^{23}$ La menor densidad del receptor $5-\mathrm{HT}_{1 \mathrm{~A}}$ en la amígdala también es consistente con la mayor actividad amigdalina de los pacientes con depleción del Trp. ${ }^{38}$ En concordancia con todo lo anterior se sabe que los antidepresivos o el tratamiento electroconvulsivo aumentan, directa o indirectamente, la señalización del receptor $5-\mathrm{HT}_{1 \mathrm{~A}}{ }^{74}$

La manipulación génica en el roedor de las proteínas que participan en la señalización del receptor $5-\mathrm{HT}_{1 \mathrm{~A}}$ también fundamenta su papel relevante en la conducta anti(mayor función) o pro-depresiva (menor función). Por ejemplo, al prolongar la señalización de este receptor, ya sea por una mutación en la subunidad $\mathrm{G}_{\text {ai2 }}$ que impide su interacción con las proteínas $\mathrm{RGS}^{76}$ o eliminando la expresión de RGS6, ${ }^{77}$ el fenotipo obtenido son ratones con conducta antidepresiva y ansiolítica. Desde luego se requiere mayor conocimiento sobre cómo el receptor $5-\mathrm{HT}_{1 \mathrm{~A}}$ regula la comunicación entre las áreas corticales y con el sistema límbico (figura 2), para elaborar hipótesis más precisas sobre su papel en la conducta afectiva y cognitiva.

La menor densidad post-sináptica del $5-\mathrm{HT}_{1 \mathrm{~A}}$ no se deriva de un mecanismo de "regulación a la baja" secundario a un déficit en la liberación de 5-HT, porque la lesión del RD no altera su densidad en la corteza y el hipocampo. ${ }^{68}$ En cambio, el eje HPA sí regula su expresión porque la extirpación, en la rata, de las glándulas adrenales aumenta el transcrito del receptor en el hipocampo, en donde el 5- $\mathrm{HT}_{1 \mathrm{~A}}$ se co-localiza con los receptores a glucocorticoides. ${ }^{78,79}$ En congruencia con lo anterior se reporta, en un modelo de estrés social, que las ratas subordinadas a un macho dominante muestran un mayor nivel de corticoesteroides y una menor densidad de los receptores $5-\mathrm{HT}_{1 \mathrm{~A}}$ en el hipocampo. ${ }^{80}$ En otro estudio se encontró que el estrés en la rata adulta atenúa la señalización del receptor $5-\mathrm{HT}_{1 \mathrm{~A}}$ en la corteza cerebral, siempre y cuando el roedor sea sometido a estrés a edad temprana. ${ }^{75}$ En el hipocampo el receptor $5-\mathrm{HT}_{1 \mathrm{~A}}$ estimula la proliferación, ${ }^{81}$ por lo que su menor densidad afectaría la neurogénesis.

\section{C) Receptores 5-HT2}

Los subtipos de receptor $5-\mathrm{HT}_{2}$ que se expresan con mayor abundancia en el cerebro son el 5- $\mathrm{HT}_{2 \mathrm{~A}}$ y el 5- $\mathrm{HT}_{2 \mathrm{C}}$. El 5- $\mathrm{HT}_{2 \mathrm{~A}}$ se expresa en el sistema límbico y la $\mathrm{CPF}$, sin embargo la evidencia sobre el sentido en que cambia su densidad en la DM es controversial ya que se reportan tanto un aumento como una disminución, o incluso sin cambio. ${ }^{82-84} \mathrm{Al}$ receptor $5-\mathrm{HT}_{2 \mathrm{~A}}$ se le relaciona más con la esquizofrenia (el antipsicótico atípico clozapina es un antagonista de este receptor) o con estados alterados de la conciencia como las alucinaciones (el LSD es un agonista de este receptor).

\section{D) Receptores a la NA}

Como ya se mencionó, pacientes con DM sin prescripción o sin trazos de antidepresivos al momento del deceso, revelan 
un aumento robusto en la densidad del receptor $\alpha_{2}$-adrenérgico en el LC. ${ }^{44}$ En el RD la densidad de este receptor no cambia, descartando que su aumento en el LC sea una respuesta compensatoria al déficit noradrenérgico. La mayor expresión del receptor $\alpha_{2}$-adrenérgico en el LC estaría reduciendo la liberación de NA en la corteza y el sistema límbico, debido a que al ubicarse pre-sinápticamente inhibe a los canales de calcio que median la liberación de neurotransmisores. ${ }^{85,86}$

\section{Tratamiento de la DM y el mecanismo de acción de los fármacos antidepresivos}

Los fármacos antidepresivos son la primera elección terapéutica, ${ }^{87,88}$ sin embargo, su eficacia es limitada ya que en promedio la tercera parte de los pacientes no responden a él. ${ }^{7}$ Otras estrategias clínicas incluyen a la terapia electroconvulsiva, la estimulación del nervio vago, la estimulación cerebral profunda o la estimulación magnética transcraneal. Una discusión del tratamiento no farmacológico puede verse en otras revisiones..$^{30,35}$

\section{El desfase entre la acción farmacológica y terapéutica de los antidepresivos}

Los antidepresivos se clasifican en: i) inhibidores selectivos de la recaptura de 5-HT (SSRIs: fluoxetina, citalopram, etc) o de la NA (NSRIs: desipramina, reboxetina); ii) de ambas monoaminas (tricíclicos: imipramina, nortriptilina); iii) inhibidores de la MAO-A (tranilcipromina, selegilina, etc). No obstante, uno de los enigmas del tratamiento farmacológico es su desfase con la acción terapéutica (de 4 a 6 semanas). Al respecto se postula que los antidepresivos inducen adaptaciones moleculares de mayor latencia y duración que están más relacionadas con su acción terapéutica. Se han logrado avances en esta dirección inyectando crónicamente (durante 2 a 3 semanas) en el roedor dosis terapéuticas del fármaco.

\section{A) Efecto sobre la vía del $A M P_{c}$}

Hay suficiente evidencia de que en la DM la vía $\mathrm{AMP}_{\mathrm{c}}$ / proteína cinasa A (PKA) ${ }^{89,90}$ es disfuncional, al igual que los procesos de plasticidad sináptica y celular dependientes del $\mathrm{AMP}_{\mathrm{c}^{\prime}}$ como la potenciación postetánica a largo plazo, el crecimiento de neuritas, la sinaptogénesis o la neurogénesis. ${ }^{90}$ Uno de los efectos moleculares de los antidepresivos es la estimulación de la vía $\mathrm{AMP}_{\mathrm{c}} / \mathrm{PKA}$ en la corteza cerebral, el hipocampo y la amígdala. ${ }^{11,92}$ Dado que entre las proteínas fosforiladas por la PKA están el factor de transcripción CREB, ${ }^{33,94}$ el cual estimula la expresión del BDNF y de su receptor $\operatorname{TrkB},{ }^{49}$ y la proteína MAP2 la cual estimula la despolimerización de los microtúbulos, ${ }^{89,92}$ se propone que parte del efecto terapéutico se debe a la estimulación de los procesos de plasticidad sináptica y celular antes referidos..$^{90}$

\section{B) Efecto sobre la expresión de las proteinas $G$}

Las proteínas $G$ heterotriméricas $\left(G_{a, \beta \gamma}\right)$ son las moléculas que primero se consideraron como posibles blancos moleculares de los antidepresivos. Esto es porque la 5-HT y NA estimulan a los receptores acoplados a estos transductores de información, con la excepción del 5- $\mathrm{HT}_{3}$. La mayor parte de los estudios publicados fueron hechos con las técnicas de western blot o ELISA. Así, en el hipotálamo la fluoxetina reduce la inmunoreactividad a $\mathrm{G}_{\text {a.1 }}(38 \%)$ y $\mathrm{G}_{a z}(27 \%)$, mientras que $G_{a i 3}, G_{a i 2}$ y $G_{0.0}$ permanecen sin cambio. ${ }^{95}$ En el neoestriado y el LC la imipramina, la clomipramina o la desipramina reducen $(20-40 \%)$ la inmunoreactividad de $\mathrm{G}_{\alpha .5} \cdot{ }^{96}$ En contraste, no hay efecto sobre la expresión de $G_{a s}, G_{\alpha i 1,2}, G_{a q / 11}$ en la corteza y/o el hipocampo, por la desipramina, ${ }^{97,98}$ amitriptilina ${ }^{97,99}$ o fluoxetina. ${ }^{100}$ Prácticamente no hay estudios que evalúen la expresión de los transcritos de las $G_{0}$. Uno de ellos emplea la técnica de northern blot y reporta que la amitriptalina y desipramina no afectan la expresión de $\mathrm{G}_{\alpha, S}$ y $\mathrm{G}_{\alpha \mathrm{i} 1 / 2}$ en la corteza cerebral. ${ }^{99}$ Otro estudio con PCR convencional muestra que la imipramina y la fluoxetina no tienen efecto sobre la expresión de $G_{a s} G_{a i 1 / 2}, G_{0.0}$ y $G_{a q}$ en la corteza frontal y el hipocampo, pero sí un aumento significativo sólo en $\mathrm{G}_{\mathrm{a} 12} \cdot{ }^{101}$

Desde hace tres décadas se conoce que los antidepresivos provocan la regulación a la baja de los receptores $\beta$-adrenérgicos ${ }^{102}$ o de otros receptores acoplados a $G_{S}(v$. gr. $\left.5-\mathrm{HT}_{4}, 5-\mathrm{HT}_{6}\right) .{ }^{91}$ Dado que $\mathrm{G}_{\mathrm{s}}$ estimula a la adenilciclasa (AC) para la síntesis de $A M P c$, la respuesta adaptativa de los receptores acoplados a $G_{S}$ se contrapone con la estimulación "rio abajo" de la vía AMPc/PKA inducido por los antidepresivos. ${ }^{91,92}$ La solución a esta paradoja puede encontrarse en $\mathrm{G}_{0 \mathrm{~S}}$, sin embargo la evidencia inmunológica no reporta cambios en la expresión de $\mathrm{G}_{\alpha . \mathrm{S}}{ }^{97-100}$ Por lo anterior, empleando las neuronas noradrenérgicas del ganglio cervical superior de la rata y la técnica de PCR en tiempo real, se encontró que el tratamiento crónico con imipramina aumenta y reduce significativamente la expresión de los transcritos de $\mathrm{G}_{a \mathrm{~s}} \mathrm{y}$ $\mathrm{G}_{a z}$, respectivamente (figura 1; datos sin publicar). El robusto cambio en la expresión de $G_{\alpha s}$ y $G_{\alpha z}$, de darse en el SNC, podría contribuir al efecto estimulante de los antidepresivos sobre la vía del AMPc.

\section{C) Efecto sobre la glicógeno sintasa cinasa $3 \beta$ (GSK-3)}

El interés por la proteína pro-apoptósica GSK-3 como blanco de los antidepresivos surge de varios hallazgos: a) se conoce que el litio, un ión con propiedad antimaniaca, es un inhibidor de esta enzima, ${ }^{103}$ al impedir su interacción con el complejo $\beta$-arrestina-fosfatasa2A-Akt; ${ }^{104}$ b) la mayor actividad de GSK-3 está asociada a alteraciones en la plasticidad neuronal, la estructura y la sobrevivencia celular; c) estudios post-mortem revelan un aumento de la actividad de GSK-3 en la CPF de individuos con $\mathrm{DM}^{105} \mathrm{y}$ d) la activación del receptor $5-\mathrm{HT}_{1 \mathrm{~A}}$ resulta en la fosforilación e inhibición 
de GSK3, en el hipocampo y la corteza del ratón. ${ }^{76}$ Si bien el agonista serotoninérgico d-fenfluramina o la fluoxetina y la imipramina inhiben a la GSK-3 en la CPF, el hipocampo y la estriado, ${ }^{106}$ es prematuro concluir que la inhibición de la GSK-3 contribuya al efecto terapéutico de los antidepresivos porque su fosforilación alcanza el máximo de 30 a 60 min después de la inyección de d-fenfluramina o fluoxetina, decayendo a su nivel basal en las siguientes horas. ${ }^{106}$

\section{D) Efectos epigenéticos}

Recientemente la epigenética ha aportado un conocimiento adicional sobre la patogénesis de la DM y el mecanismo de acción de los antidepresivos. ${ }^{107}$ En este enfoque se le atribuye al estrés crónico un papel relevante en la interacción del medioambiente con la carga génica del individuo, siendo la acetilación (activador de la expresión) y/o la metilación (inhibidor de la expresión) de las histonas el mecanismo molecular por el cual el estrés modifica el patrón de expresión génica.

Tsankova et al. ${ }^{108}$ encontraron que el estrés por rechazo social inhibe en el hipocampo del roedor la expresión de BDNF y aumenta la metilación de la histona H3-K27; en tanto que la imipramina revierte el efecto sobre el BDNF al inhibir la expresión de la histona deacetilasa-5 (Hdac5) generando subsecuentemente un aumento en la acetilación de la histona H3. Consistentemente con lo anterior, la sobreexpresión en el hipocampo de Hdac5 revierte el efecto conductual de la imipramina, la cual promueve la conducta de socialización. ${ }^{108}$ Otro estudio muestra que la infusión en el NAc del inhibidor de las Hdac, el MS-275, tiene efectos antidepresivos en las pruebas de rechazo social y FST. ${ }^{109}$

El mecanismo epigenético también contribuye a la vulnerabilidad al estrés. Por ejemplo, el estrés social produce en el NAc aumento en la metilación de 1285 genes; notablemente la imipramina revierte el grado de metilación con un perfil génico semejante al encontrado en los ratones que toleran la presencia del macho agresivo. ${ }^{110}$ Uchida et al., ${ }^{111}$ empleando dos cepas de ratones, una vulnerable (BALB/c) y otra resistente (C57BL/6) al estrés crónico físico, sugieren que uno de los genes cuyo nivel de expresión se correlaciona con la vulnerabilidad o la tolerancia al estrés es el del factor neurotrófico derivado de la glia (GDNF). Por ejemplo, la cepa BALB/c responde al estrés reduciendo tanto la acetilación de $\mathrm{H} 3$ como la expresión del GDNF (estos efectos se revierten con la imipramina); en contraste, la C57BL/ 6 responde de manera opuesta al estres. ${ }^{111}$ Las pruebas conductuales revelan que el nivel de expresión del GDNF se correlaciona positivamente con la prueba que valora la conducta de interacción social y hedónica, pero no con la FST. Estos hallazgos sugieren que en el humano algunas conductas depresivas tienen su base molecular en cambios en el nivel de expresión de genes específicos y en áreas definidas del SNC.

\section{E) Otros blancos moleculares}

Otra proteína cuya expresión es inhibida por la imipramina es la proteína p21. ${ }^{112}$ Esta proteína es un inhibidor de las cinasas dependientes de ciclinas y, por ende, regula la proliferación celular. Se postula que la inhibición de la expresión de p21 es parte del mecanismo mediante el cual los antidepresivos estimulan la neurogénesis en el hipocampo. ${ }^{112}$ Sin embargo, no es claro si la neurogénesis en el hipocampo es indispensable para el efecto antidepresivo observado en la prueba FST. Lo anterior se plantea porque cuando se inhibe la neurogénesis por irradiación con rayos $\mathrm{X}$ del hipocampo, la fluoxetina continúa ejerciendo su acción antidepresiva en la prueba FST. ${ }^{113}$

Otro blanco molecular de los antidepresivos es la proteína p11. Esta molécula de señalización interacciona con los receptores $5-\mathrm{HT}_{1 \mathrm{~B}}$ y $5-\mathrm{HT}_{4}$, y su expresión está reducida en la CCA y NAc de pacientes con DM. ${ }^{114}$ En el roedor, la fluoxetina, la imipramina y la tranilcipromina, pero no el NSRI desipramina, estimulan la expresión de p11 en la corteza frontal y el hipocampo. ${ }^{114,115}$ Además, citoquinas como el interferón- $\gamma$ y TNF- $\alpha$ aumentan la expresión de p11. ${ }^{115}$ Se desconoce el grado de entrecruzamiento de las vías de señalización estimuladas por las citoquinas (efecto en cuatro hrs) y los antidepresivos (efecto en 14 días). Otro dato revelador es que los fármacos anti-inflamatorios no esteroideos (NSAIDs) reducen la eficacia de los SSRIs para aumentar la expresión de p11, y este antagonismo se extiende a su efecto antidepresivo en la prueba FST y la DM. ${ }^{115}$ En contraste, los NSAIDs aumentan la eficacia terapéutica del NSRI reboxetina. ${ }^{116}$ En conjunto todos estos hallazgos sugieren que existe una divergencia en el mecanismo molecular que subyace a la acción terapéutica de los SSRIs y los NSRIs.

\section{CONCLUSIÓN}

Distintos mecanismos pueden causar el déficit de la transmisión serotoninérgica. En algunos casos tiene bases genéticas como el polimorfismo G1463A en el gen de la enzima hTPH2 o el C(-1019)G en el gen del receptor 5- $\mathrm{HT}_{1 \mathrm{~A}}$; el primero reduce la síntesis de 5-HT mientras que el segundo atenúa su liberación. Desde esta perspectiva se sugiere que el diagnostico de DM incluya un estudio de genética molecular para identificar estos polimorfismos. Además, se infiere que los portadores del polimorfismo C(-1019)G responderán mejor a la combinación de SSRI con algún antagonista del $5-\mathrm{HT}_{1 \mathrm{~A}}$. La menor densidad postsináptica del receptor $5-\mathrm{HT}_{1 \mathrm{~A}}$ también es un mecanismo fisiopatológico relevante porque su acción inhibitoria sobre la excitabilidad neuronal es consistente con el hipermetabolismo del área Cg25 y la amígdala. Estos cambios metabólicos pueden revelar la disfunción de los circuitos intra-corticales y límbico-corticales (figura 2). En este contexto, se sugiere que el diagnóstico se 
acompañe de un estudio con PET, para confirmar la menor densidad cortical del 5- $\mathrm{HT}_{1 \mathrm{~A}}$.

Los estudios pre-clínicos indican que el estrés reduce la expresión del BDNF y GDNF, del receptor 5- $\mathrm{HT}_{1 \mathrm{~A}}, \mathrm{y}$ provoca atrofia dendrítica en el hipocampo. El efecto sobre la expresión de los factores de crecimiento opera mediante mecanismos epigenéticos, ya sea aumentando la metilación o reduciendo la acetilación de la histona H3. La imipramina revierte estos efectos al inhibir en el hipocampo la expresión de la Hdac5 y, por ende, aumentando la acetilación de $\mathrm{H} 3$ y la expresión del BDNF. En el NAc el tricíclico reduce la expresión de Hdac2, aumentando la expresión del GDNF. La latencia de los efectos epigenéticos de la imipramina coincide con la latencia de su acción terapéutica. Es probable que el efecto inhibitorio del estrés sobre la expresión del $5-\mathrm{HT}_{1 \mathrm{~A}}$ sea por un mecanismo epigenético. En el hipocampo el receptor $5-\mathrm{HT}_{1 \mathrm{~A}}$ también tiene efectos proliferativos y neurogénicos, aunque se desconoce si el BDNF interviene en la acción del receptor.

Un efecto celular común de los antidepresivos es la estimulación de la vía AMPc/PKA y la subsecuente estimulación de genes regulados por el factor de transcripción CREB, incluyendo el BDNF. Aquí demostramos que la imipramina aumenta la expresión de $\mathrm{G}_{a \mathrm{~s}}$ (estimulador de la $\mathrm{AC}$ ) y reduce la expresión de $\mathrm{G}_{a \mathrm{z}}$ (inhibidor de la $\mathrm{AC}$ ). Estos cambios en la expresión son consistentes con la estimulación de la vía del AMPc.

El efecto clínico antagónico de los NSAIDs sobre los SSRIs, pero no sobre los NSRIs, sugiere que es relevante identificar con mayor precisión la etiología de la DM para definir (SSRIs vs. NSRIs) la apropiada estrategia farmacológica.

\section{Financiamiento}

Este trabajo fue parcialmente subvencionado por el Consejo Nacional de Ciencia y Tecnología (donativo 168734).

\section{Conflictos de interés}

Los autores declaran no tener conflictos de interés.

\section{REFERENCIAS}

1. Albert PR, Benkelfat C, Descarries L. The neurobiology of depression: revisiting the serotonin hypothesis. I. Cellular and molecular mechanisms. Phil Trans R Soc B 2012;367:2378-2381.

2. Lee S, Jeong J, Kwak Y, Park SK. Depression research: where are we now? Molecular Brain 2010;3:1-10.

3. Hyman SE. A glimmer of light for neuropsychiatric disorders. Nature 2008;455:890-893.

4. Murray CJ, Lopez AD. Evidence-based health policy-lessons from the global burden of disease. Science 1996;274:740-743.

5. Belló M, Puentes-Rosas E, Medina-Mora ME, Lozano R. Prevalencia y diagnóstico de depresión en población adulta en México. Salud Pública Méx 2005; 47(sup11):s4-s11.

6. Benjet C, Borges G, Medina-Mora ME, Fleiz-Bautista C et al. La depresión con inicio temprano: prevalencia, curso natural y latencia para buscar tratamiento. Salud Pública Méx 2004;46:417-424.
7. Belmaker RH, Agam G. Major depressive disorder. N Engl J Med 2008;358:55-68.

8. Hasler G, Drevets WC, Manji HK, Charney DS. Discovering endophenotypes of major depression. Neuropsychopharmacology 2004;29:1765-1781.

9. Krishnan V, Nestler EJ. The molecular neurobiology of depression. Nature 2008;455:894-902.

10. Mill J, Petronis A. Molecular studies of major depressive disorder: the epigenetic perspective. Mol Psychiatry 2007;12:799-814.

11. Bissette G, Klimek V, Pan J, Stockmeier C et al. Elevated concentration of CRF in the locus coeruleus of depressed subjects. Neuropsychopharmacology 2003;28:1328-1335.

12. Brown ES, Varghese FP, McEwen BS. Association of depression with medical illness: Does cortisol play a role? Biol Psychiatry 2004;55:1-9.

13. Wong M-L, Kling MA, Munson PJ, Listwak S et al. Pronounced and sustained central hypernoradrenergic function in major depression with melancholic features: Relation to hypercortisolism and corticotropin-releasing hormone. Proc Natl Acad Sci USA 2000;97:325-330.

14. Holsboer F. The corticosteroid receptor hypothesis of depression. Neuropsychopharmacology 2000;23:477-501.

15. Campbell S, MacQueen G. The role of the hippocampus in the pathophysiology of major depression. J Psychiatry Neurosci 2004;29:417426.

16. Drevest WC, Gadde KM, Krishnan RR. Neuroimaging studies of mood disorders. En: Charney DS, Nestler EJ (eds). Neurobiology of mental illness. Nueva York: Oxford University Press; 2004; pp.461-490.

17. MacMaster FP, Kusumakar V. Hippocampal volume in early onset depression. BMC Med 2004;2:1-6.

18. MacQueen GM, Campbell S, McEwen BS, Macdonald K et al. Course of illness, hippocampal function, and hippocampal volume in major depression. Proc Natl Acad Sci USA 2003;100:1387-1392.

19. Sheline YI, Sanghavi M, Mintun MA, Gado MH. Depression duration but no age predicts hippocampal volume loss in medically healthy women with recurrent major depression. J Neurosci 1999;19:50345043.

20. Campbell S, Marriott M, Nahmias C, MacQueen GM. Lower hippocampal volume in patients suffering from depression: A meta-analysis. Am J Psychiatry 2004;161:598-607.

21. Neumeister A, Wood S, Bonne O, Nugent AC et al. Reduced hippocampal volume in unmedicated, remitted patients with major depression versus control subjects. Biol Psychiatry 2005;57:935-937.

22. Shenton ME, Kikinis R, Jolesz FA, Pollak SD et al. Abnormalities of the left temporal lobe and thought disorder in schizophrenia. A quantitative magnetic resonance imaging study. N Engl J Med 1992;327:604-612.

23. Maletic V, Robinson M, Oakes T, Iyengar S et a. Neurobiology of depression: an integrated view of key findings. Int J Clin Pract 2007;61:2030-2040.

24. Hajek T, Kozeny J, Kopecek M, Alda M et al. Reduced subgenual cingulate volumes in mood disorders: a meta-analysis. J Psychiatry Neurosci 2008;33:91-99.

25. Bremner JD, Vythilingam M, Vermetten E, Nazeer A et al. Reduced volume of orbitofrontal cortex in major depression. Biol Psychiatry 2002;51:273-279.

26. Öngür D, Drevest WC, Price JL. Glial reduction in the subgenual prefrontal cortex in mood disorders. Proc Natl Acad Sci USA 1998;95:13290-13295.

27. Carretié L, López-Martin S, Albert J. Papel de la corteza prefrontal ventromedial en la respuesta a eventos emocionalmente negativos. Rev Neurol 2010;50:245-252.

28. Fuster JM. The prefrontal cortex-an update: Time is of the essence. Neuron 2001;30:319-333. 
29. Drevets WC, Price JL, Simpson JR Jr, Todd RD et al. Subgenual prefrontal cortex abnormalities in mood disorders. Nature 1997;386:824827.

30. Ressler KJ, Mayberg HS. Targeting abnormal neural circuits in mood and anxiety disorders: from the laboratory to the clinic. Nature Neurosci 2007;10:1116-1124.

31. Drevets WC, Bogers W, Raichle ME. Functional anatomical correlates of antidepressant drug treatment assessed using PET measures of regional glucose metabolism. Eur J Neuropharmacol 2002;12:527-544.

32. Goldapple K, Segal Z, Garson C, Lau M et al. Modulation of specific cortical-limbic pathways in major depression: treatment-specific effects of cognitive behavior therapy. Arch Gen Psychiatry 2004;61:34-41.

33. Kennedy SH, Konarski JZ, Segal ZV, Lau MA et al. Differences in brain glucose metabolism between responders to $C B T$ and venlafaxine in a 16-week randomized controlled trial. Am J Psychiatry 2007;164:778788.

34. Wagner G, Koch $K$, Schachtzabel C, Sobanski $T$ et al. Differential effects of serotoninergic and noradrenergic antidepressants on brain activity during a cognitive control task and neurofunctional prediction of treatment outcome in patients with depression. J Psychiatry Neurosci 2010;35:247-257.

35. Kuhn J, Gründler TOJ, Lenartz D, Stum V et al. Deep brain stimulation for psychiatric disorders. Dtsch Arztebl Int 2010;107:105-113.

36. Mayberg HS, Lozano AM, Voon V, McNeely HE et al. Deep brain stimulation for treatment-resistant depression. Neuron 2005;45:651-660.

37. Drevets $\mathrm{CW}$, Videen TO, Price JL, Preskorn SH et al. A functional anatomical study of unipolar depression. J Neurosci 1992;12:3628-3641.

38. Bremner JD, Innis RB, Solomon RM, Staib LH et al. Positron emission tomography measurement of cerebral metabolic correlates of tryptophan depletion-induced depressive relapse. Arch Gen Psychiatry 1997;54:364-374.

39. Meyer JH, Ginovart N, Boovariwala A, Sagrati S et al. Elevated monoamine oxidase A levels in the brain. An explanation for the monoamine imbalance of major depression. Arch Gen Psychiatry 2006;63:12091216.

40. Zhang X, Gainetdinov RR, Beaulieu J-M, Sotnikova TD et al. Loss-offunction mutation in tryptophan hydroxilase-2 identified in unipolar depression. Neuron 2005;45:11-16.

41. Ruhé HG, Mason NS, Schene AH. Mood is indirectly related to serotonin, norepinephrine and dopamine levels in humans: a meta-analysis of monoamine depletion studies. Mol Psychiatry 2007;12:331-359.

42. Hasler G, Fromm S, Carlson PJ, Luckenbaugh DA et al. Neural response to cathecolamine depletion in unmedicated subjects with major depressive disorder in remission and healthy subjects. Arch Gen Psychiatry 2008;65:521-531.

43. Klimek V, Stockmeier C, Overholser J, Meltzer HY et al. Reduced levels of norepinephrine transporters in the locus coeruleus in major depression. J Neurosci 1997;17:8451-8458.

44. Ordway GA, Schenk J, Stockmeier CA, May W et al. Elevated agonist binding to $\alpha_{2}$-adrenoreceptors in the locus coeruleus in major depression. Biol Psychiatry 2003;53:315-323.

45. Martinowich K, Manji H, Lu B. New insights into BDNF function in depression and anxiety. Nature Neurosci 2007;10:1089-1093.

46. Dwivedi Y, Rizavi HS, Conley RR, Roberts RC et al. Altered gene expression of brain-derived neurotrophic factor and receptor tyrosine kinase B in postmortem brain of suicide subjects. Arch Gen Psychiatry 2003;60:804-815.

47. Chen B, Dowlatshahi D, MacQueen GM, Wang J-F et al. Increased hippocampal BDNF inmunoreactivity in subjects treated with antidepressant medication. Biol Psychiatry 2001;50:260-265.

48. Groves JO. Is it time to reassess the BDNF hypothesis of depression? Mol Psychiatry 2007;12:1079-1088.
49. Nibuya M, Morinobu S, Duman RS. Regulation of BDNF and trkB mRNA in rat brain by chronic electroconvulsive seizure and antidepressant drug treatments. J Neurosci 1995;15:7539-7547.

50. Saarelainen T, Hendolin P, Lucas G, Koponen E et al. Activation of the trkB neurotrophin receptor is induced by antidepressant drugs and is required for antidepressant-induced behavioral effects. J Neurosci 2003;23:349-357.

51. Nestler EJ, Barrot M, DiLeone RJ, Eisch AJ et al. Neurobiology of depression. Neuron 2002;34:13-25.

52. Norrholm SD, Quimet CC. Altered dendritic spine density in animal models of depression and in response to antidepressant treatment. Synapse 2001;42:151-163.

53. Malberg JE, Eisch AJ, Nestler EJ, Duman RS. Chronic antidepressant treatment increases neurogenesis in adult rat hippocampus. J Neurosci 2000;20:9104-9110.

54. Santarelli L, Saxe M, Gross C, Surget A et al. Requirement of hippocampal neurogenesis for the behavioral effect of antidepressants. Science 2003;301:805-809.

55. Reed AL, Happe HK, Petty F, Bylund DB. Juvenile rats in the force-swim test model the human response to antidepressants treatment for pediatric depression. Psychopharmacology 2008;197:433-441.

56. Shirayama Y, Chen AC-H, Nakagawa S, Russell DS et al. Brain-derived neurotrophic factor produces antidepressant effects in behavioral models of depression. J Neurosci 2002;22:3251-3261.

57. Lemonde S, Turecki G, Bakish D, Du L et al. Impaired repression at a 5-hidroxytriptamine $1 \mathrm{~A}$ receptor gene polymorphism associated with major depression and suicide. J Neurosci 2003;23:8788-8799.

58. Hesselgrave N, Parsey RV. Imaging the serotonin 1A receptor using $\left[{ }^{11} \mathrm{C}\right]$ WAY100635 in healthy controls and major depression. Phil Trans R Soc B 2013;368:20120004. http//dx.doi.org/10.1098/rstb.2012.0004.

59. Parsey RV, Olvet DM, Oquendo MA, Huang Y-Y et al. Higher $5-\mathrm{HT}_{1 \mathrm{~A}}$ receptor binding potential during a major depressive episode predicts poor treatment response: preliminary data from a naturalistic study. Neuropsychopharmacology 2006;31:1745-1749.

60. Richardson-Jones JW, Craige CP, Guiard BP, Stephen A et al. 5- $\mathrm{HT}_{1 \mathrm{~A}}$ receptor levels determine vulnerability to stress and response to antidepressants. Neuron 2010;65:40-52.

61. Artigas F, Romero L, De Montigny C, Blier P. Acceleration of the effect of selected antidepressant drugs in major depression by $5-\mathrm{HT}_{1 \mathrm{~A}}$ antagonists. Trends Neurosci 1996;19:378-383.

62. Celada P, Puig V, Amargós-Bosch M, Adell A et al. The therapeutic role of 5- $\mathrm{HT}_{1 \mathrm{~A}}$ and $5-\mathrm{HT}_{2 \mathrm{~A}}$ receptors in depression. J Psychiatry Neurosci 2004;29:252-265.

63. Castro ME, Diaz A, Del Olmo E, Pazos A. Chronic fluoxetine induces opposite changes in $\mathrm{G}$ protein coupling at pre and postsynaptic $5-\mathrm{HT}_{1 \mathrm{~A}}$ receptors in rat brain. Neuropharmacology 2003;44:93-101.

64. Hensler JG. Differential regulation of $5-\mathrm{HT}_{1 \mathrm{~A}}$ receptor-G protein interactions in brain following chronic antidepressant administration. Neuropsychopharmacology 2002;26:565-573.

65. Pejchal T, Foley MA, Kosofsky BE, Waeber C. Chronic fluoxetine treatment selectively uncouples raphe $5-\mathrm{HT}_{1 \mathrm{~A}}$ receptors as measured by [ ${ }^{35}$ S]-GTP $\gamma S$ autoradiography. Br J Pharmacol 2002;135:1115-1122.

66. Sargent PA, Kjaer KH, Bench CJ, Rabiner EA et al. Brain serotonin1A receptor binding measured by positron emission tomography with $\left[{ }^{11} \mathrm{C}\right]$ WAY-100635. Arch Gen Psychiatry 2000;57:174-180.

67. Bhagwagar Z, Rabiner EA, Sargent PA, Grasby PM et al. Persistent reduction in brain serotonin1 $A$ receptor binding in recovered depressed men measured by positron emission tomography with $\left[{ }^{11} \mathrm{C}\right]$ WAY100635. Mol Psychiatry 2004;9:386-392.

68. Drevets WC, Frank E, Price JC, Kupfer DJ et al. PET imaging of serotonin 1A receptor binding in depression. Biol Psychiatry 1999;46:13751387. 
69. Savitz J, Lucki I, Drevets WC. $5-\mathrm{HT}_{1 \mathrm{~A}}$ receptor function in major depressive disorder. Prog Neurobiol 2009;88:17-31.

70. Lanzenberger RR, Mitterhauser M, Spindelegger C, Wadsak $W$ et al. Reduced serotonin-1A receptor binding in social anxiety disorder. Biol Psychiatry 2007;61:1081-1089.

71. Neumeister A, Bain E, Nugent AC, Carson RE et al. Reduced serotonin type 1A receptor binding in panic disorder. J Neurosci 2004;24:589591.

72. Azmitia EC, Gannon PJ, Kheck NM, Whitaker-Azmitia PM. Cellular localization of the $5-\mathrm{HT}_{1 \mathrm{~A}}$ receptor in primate brain neurons and glial cells. Neuropsychopharmacology 1996;14:35-46.

73. Puig MV, Celada P, Artigas F. Control serotoninérgico de la corteza prefrontal. Rev Neurol 2004;39:539-547.

74. Riad M, Garcia S, Watkins KC, Jodoin N et al. Somatodendritic localization of $5-\mathrm{HT}_{1 \mathrm{~A}}$ and preterminal axonal localization of $5-\mathrm{HT}_{1 \mathrm{~B}}$ serotonin receptors in adult rat brain. J Comp Neurol 2000;417:181-194.

75. Goodfellow NM, Benekareddy M, Vaidya VA, Lambe EK. Layer II/III of the prefrontal cortex: Inhibition by the serotonin $5-\mathrm{HT}_{1 \mathrm{~A}}$ receptor in development and stress. J Neurosci 2009;29:10094-10103.

76. Talbot JN, Jutkiewicz EM, Graves SM, Clemans CF et al. RGS inhibition at $\mathrm{Gó}_{\mathrm{i} 2}$ selectively potentiates $5-\mathrm{HT}_{1 \mathrm{~A}}$-mediated antidepressant effects. Proc Natl Acad Sci USA 2010;107:11086-11091.

77. Stewart A, Maity B, Wunsch AM, Meng F et al. Regulator of G-protein signaling 6 (RGS6) promotes anxiety and depression by attenuating serotonin mediated activation of the $5-\mathrm{HT}_{1 \mathrm{~A}}$ receptor-adenylyl cyclase axis. FASEB J 2014;28:1735-1744.

78. Chalmers DT, Kwak SP, Mansour A, Akil $\mathrm{H}$ et al. Corticosteroids regulate brain hippocampal $5-\mathrm{HT}_{1 \mathrm{~A}}$ receptor mRNA expression. J Neurosci 1993;13:914-923.

79. Checkley $S$. The neuroendocrinology of depression and chronic stress. Br Med Bull 1996;52:597-617.

80. McKittrick CR, Blanchard DC, Blanchard RJ, McEwen BS et al. Serotonin receptor binding in a colony model of chronic social stress. Biol Psychiatry 1995;37:383-393.

81. Banasr M, Hery M, Printemps R, Daszuta A. Serotonin-induces increases in adult cell proliferation and neurogenesis are mediated through different and common 5-HT receptor subtypes in the dentate gyrus and the subventricular zone. Neuropsychopharmacology 2004;29:450460.

82. Meyer JH, Kapur S, Houle S, DaSilva J et al. Prefrontal cortex 5-HT receptors in depression: An $\left[{ }^{18} \mathrm{~F}\right]$ setoperone PET imaging study. Am J Psychiatry 1999;156:1029-1034.

83. Pandey GN, Dwivedy Y, Rizavi HS, Ren X et al. et al. Higher expression of serotonin $5-\mathrm{HT}_{2 \mathrm{~A}}$ receptors in the postmortem brains of teenage suicide victims. Am J Psychiatry 2002;159:419-429.

84. Yatham LN, Liddle PF, Shiah I-S, Scarrow G et al. Brain serotononin 2 receptors in major depression. Arch Gen Psychiatry 2000;57:850-858.

85. Stephens GJ, Mochida S. G protein $\beta \gamma$ subunits mediate presynaptic inhibition of transmitter release from rat superior cervical ganglion neurones in culture. J Physiol 2005;563:765-776.

86. Jewell ML, Currie KPM. Control of Cav2 calcium channels and neurosecretion by heterotrimeric $\mathrm{G}$ protein coupled receptors. En: Stephens G, Mochida S (eds.). Modulation of presynaptic calcium channels. New York: Springer; 2013; p.101-130.

87. Mathew SJ, Manji HK, Charney DS. Novel drugs and therapeutic targets for severe mood disorders. Neuropsychopharmacology 2008;33:2080-2092.

88. Rot M, Mathew SJ, Charney DS. Neurobiological mechanisms in major depressive disorder. CMAJ 2009;180:305-313.

89. Dwivedi Y, Pandey GN. Adenylyl cyclase-cyclicAMP signaling in mood disorders: Role of the crucial phosphorylating enzyme protein kinase A. Neuropsychiatric Disease Treatment 2008;4:161-176.
90. Pittenger C, Duman RS. Stress, depression, and neuroplasticity: A convergence of mechanisms. Neuropsychopharmacology 2008;33:88109.

91. Nestler EJ, Hyman SE, Malenka RC. Molecular neuropharmacology: A Foundation for Clinical Neuroscience. Segunda ed. New York: McGraw-Hill; 2009.

92. Tardito D, Perez J, Tiraboschi E, Musazzi L et al. Signaling pathways regulating gene expression, neuroplasticity, and neurotrophic mechanisms in the action of antidepressants: A critical overview. Pharmacol Rev 2006;58:115-134.

93. Nair A, Vaidya VA. Cyclic AMP response element binding protein and brain-derived neurotrophic factor: molecules that modulate our mood? J Biosci 2006;31:423-434.

94. Thome J, Sakai N, Shin K-H, Steffen C et al. cAMP response element-mediated gene transcription is upregulated by chronic antidepressant treatment. J Neurosci 2000;20:4030-4036.

95. Raap DK, Evans S, Garcia F, Li Q et al. Daily injections of fluoxetine induce dose-dependent desensitization of hypothalamic $5-\mathrm{HT}_{1 \mathrm{~A}}$ receptors: Reductions in neuroendocrine responses to 8-OH-DPAT and in levels of Gz and Gi proteins. J Pharmacol Exp Ther 1999;288:98-106.

96. Lesch KP, Aulakh CS, Tolliver TJ, Hill JL et al. Regulation of G proteins by chronic antidepressant drug treatment in rat brain: tricyclics but not clorgyline increase $G_{0 u}$ subunits. Eur J Pharmacol 1991;207:361-364.

97. Chen J, Rasenick MM. Chronic antidepressant treatment facilitates G protein activation of adenylyl cyclase without altering $G$ protein content. J Phamacol Exp Ther 1995;275:509-517.

98. Dwivedi Y, Pandey GN. Effect of subchronic administration of antidepressants and anxiolytics on levels of $\alpha$ subunits of $G$ proteins in the rat brain. J Neural Transm 1997;104:747-760.

99. Emamghoreishi M, Warsh JJ, Sibony D, Li PP. Lack of effect of chronic antidepressant treatment on Gs and Gi $\alpha$-subunit protein and mRNA levels in the rat cerebral cortex. Neuropsychopharmacology 1996;15:281-287.

100. Li Q, Muma NA, Battaglia G, Van de Kar LD. Fluoxetine gradually increases [ $\left.{ }^{125} \mathrm{I}\right] \mathrm{DOI}-$ labelled $5-\mathrm{HT}_{2 \mathrm{~A} / 2 \mathrm{C}}$ receptors in the hypothalamus without changing the levels of $\mathrm{G}_{\mathrm{q}}$ - and G11-proteins. Brain Res 1997;775:225-228.

101. Lesch KP, Manji HK. Signal-transducing G proteins and antidepressant drugs: evidence for modulation of $\alpha$ subunit gene expression in rat brain. Biol Psychiatry 1992;32:549-579.

102. Vetulani J, Stawarz RJ, Dingell JV, Sulser F. A possible common mechanism of action of antidepressant treatments: reduction in the sensitivity of the noradrenergic cyclic AMP generating system in the rat limbic forebrain. Naunyn-Schmiedeberg's Arch Pharmacol 1976;293:109-114.

103. Klein PS, Melton DA. A molecular mechanism for the effect of lithium on development. Proc Natl Acad Sci USA 1996;93:8455-8459.

104. Beaulieu J-M, Marion S, Rodriguiz RM, Medevev IO et al. A $\beta$-arresting signaling complex mediates lithium action on behavior. Cell 2008;132:125-136.

105. Karege F, Perroud N, Burkhardt S, Schwald M et al. Alteration in kinase activity but not in protein levels of protein kinase B and glycogen synthase kinase-3 $\beta$ in ventral prefrontal cortex of depressed suicide victims. Biol Psychiatry 2007;61:240-245.

106. Li X, Zhu W, Roh M-S, Friedman AB et al. In vivo regulation of glyco-

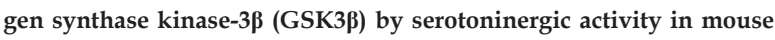
brain. Neuropsychopharmacology 2004;29:1426-1431.

107. Vialou V, Feng J, Robison AJ, Nestler EJ. Epigenetic mechanisms of depression and antidepressant action. Annu Rev Pharmacol Toxicol 2013;53:59-87.

108. Tsankova NM, Berton O, Renthal W, Kumar A et al. Sustained hippocampal chromatin regulation in a mouse model of depression and antidepressant action. Nature Neurosci 2006;9:519-525. 
109. Covington HE III, Maze I, LaPlant QC, Vialou VF et al. Antidepressant actions of histone deacetylase inhibitors. J Neurosci 2009;29:11451-11460.

110. Wilkinson MB, Xiao G, Kumar A, LaPlant $Q$, Renthal W et al. Imipramine treatment and resiliency exhibit similar chromatin regulation in the mouse nucleus accumbens in depression models. J Neurosci 2009;29:7820-7832.

111. Uchida S, Hara K, Kobayashi A, Otsuki K et al. Epigenetic status of Gdnf in ventral striatum determines susceptibility and adaptation to daily stressful events. Neuron 2011;69:359-372.

112. Pechnick RN, Zonis S, Wawrowsky K, Pourmorady J et al. p21Cip1 restricts neuronal proliferation in the subgranular zone of the dentate gyrus of the hippocampus. Proc Natl Acad Sci USA 2008;105:1358-1363.

113. David DJ, Samuels BA, Rainer $Q$, Wang J-W et al. Neurogenesis-dependent and -independent effects of fluoxetine in an animal model of anxiety/depression. Neuron 2009;62:479-493.
114. Svenningsson $P$, Cherguri $K$, Rachleff $I$, Flajolet $M$ et al. Alterations in $5-\mathrm{HT}_{1 \mathrm{~B}}$ receptor function by $\mathrm{p} 11$ in depression-like states. Science 2006;311:77-80.

115. Warner-Schmidt JL, Vanover KE, Chen EY, Marshall JJ et al. Antidepressant effects of selective serotonin reuptake inhibitors (SSRIs) are attenuated by antiinflamatory drugs in mice and humans. Proc Natl Acad Sci USA 2011;108:9262-9267.

116. Müller N, Schwarz MJ, Dehning S, Douhe A et al. The cyclooxygenase-2 inhibitor celecoxib has therapeutic effects in major depression: results of a double-blind, randomized, placebo controlled, add-on pilot study to reboxetine. Mol Psychiatry 2006;11:680-684. 